\title{
Self-Regulated Learning and the Role of ePortfolios in Business Studies
}

\section{Amparo S. Dominguez ${ }^{1}$, Lucia Morales ${ }^{2}$, Valentina Tarkovska ${ }^{2}$}

\begin{abstract}
Through a case study supported by observation techniques, and questionnaires to gather data, we explored the use of ePortfolios as an efficient assessment tool to assist business degree students. Our main focus was a postgraduate course in which finance modules were a major component. We analysed the role of ePortfolios in Higher Education Institutions over a period of four academic years. Our findings suggest that ePortfolios could be used to facilitate and enhance students' selfregulated learning. The role of the instructor was found to be fundamental in the early stages of the learning process. This role diminished as students became familiar with the course requirements. Overall, students judged the ePortfolio as a tool to complement their education positively, as they noted a significant improvement in their learning experience and they benefitted from the breaks it offered from their traditional learning approach. The evidence suggests that ePortfolios could be used to support technical and complex modules in a controlled environment where support is available for students to prevent them losing focus on their core studies; at the same time ePortfolios are flexible enough to allow students to be creative and integrate their own ideas and views while they learn.
\end{abstract}

Keywords: ePortfolios, assessment, feedback, finance, self-regulated learning.

\footnotetext{
${ }^{1}$ Finance and Accounting Department, Universitat Jaume I, Castello de la Plana, Spain

2 Department of Accounting and Finance, Dublin Institute of Technology, Dublin, Ireland
} 


\section{$1 \quad$ Introduction}

The educational system in general and higher education institutions (HEIs) in particular are experiencing a profound change in learning and teaching processes and methodologies. Conventional procedures are evolving towards greater student participation known as the "student centred approach" in detriment to traditional methods of teaching in which the instructor was the focus of attention. Following this change in the learning and teaching paradigm, standards have been laid down by the European Higher Education Area (EHEA, 2010), which seeks to establish quality assurance procedures across the educational system. Its objective is to guarantee the quality of higher education programmes and qualifications, by enabling instructors and students to become more competent and have their qualifications recognised fairly in the European context. Investing in the formation of professionals who can integrate in challenging and changing environments is essential for countries to grow and develop. At the centre of the formation process are HEIs, which should help students to take control of their own learning, development and progress. These characteristics are fundamental to ensure that future professionals are equipped with the skills required to face the challenges of a shifting and very demanding labour market. In this regard, we consider that lifelong learning strategies should foster students' ability to self-regulate and monitor their own learning needs. The educational system should act as a supporter and mediator to develop and enhance students' skills and self-awareness of their own responsibility for their education. HEIs should ensure, through monitoring, that higher standards become a conduit of knowledge and good practices that allow students to face the challenges of a competitive and dynamic working environment. In this regard, learners should receive support from the educational system that, with the help of new technologies, should offer alternatives to them and their potential employers, thereby satisfying their needs and equipping them with skills that contribute to social cohesion and to fostering equal 
opportunities among highly qualified professionals.

We identify technology as a key factor in inducing the development and transmission of knowledge. Technology has played a significant role in favouring the emergence of new assessment tools that promote a blended learning style which empowers students who are seeking greater autonomy and self-control in their education. One of these tools is the ePortfolio. This tool seems to fit perfectly with the holistic perception in which the student is encouraged to take ownership of his/her learning in an autonomous and reflective manner. Existing research (Barr and Tagg, 1995 and Black and William, 1998) argues that ePortfolios contribute to enhancing students' sympathy towards self-regulated learning. Bogdan and Biklen (1998) argue that, "Self-regulated learning is an active and constructive process, whereby learners set goals for their learning and monitor, regulate, and control their cognition, motivation, and behaviour, guided and constrained by their goals and the contextual features of the environment" (p.64). We therefore propose that self-regulated learning could be promoted by the use of ePortfolios, as students are challenged to take an active role in the knowledge-generating process. To test our proposal, we conducted a case study to explore whether ePortfolios can be considered as an effective tool to promote reflective learning among graduate students in the financial field. It is our view that business students specialising in finance should be able to reflect and apply knowledge in their workplace, and we want to understand whether these skills can be nurtured and transmitted to students by using ePortfolios in postgraduate programmes.

The extant literature has dealt widely with the potential use of this versatile tool for assessment purposes (Butler, and Winne, 1995; DeCorte, 1996; Nicol, 1997 and Nicol and Macfarlane, 2007). In this paper, we aim to contribute to the research in this field by identifying the potential of ePortfolios as a resource that can enhance the learning process, while preparing and equipping students with the necessary skills for the development of their professional career. Our main focus is to study ePortfolios as a complementary feature of the learning and teaching strategy to 
support graduate students in the field of finance, as we have identified a clear gap in the research referring to the potential of the tool as a self-reflective instrument in the area of finance. The ePortfolio is conceived as a virtual personal space of work where participants benefit from working on line, balanced with instructors' and peers' feedback. Moreover, capabilities such as autonomy, self-management and creativity are encouraged to add quality to students' work outcomes. In addition, users of ePortfolios are able to develop and strengthen the critical thinking skills that emerge during and after the reflection process that takes place while they assimilate contents.

\subsection{Study Objectives and Research Questions}

This study provides a general evaluation of how ePortfolios can be used efficiently to support business studies students. Our main focus of interest lies in how the tool could be used to support students' learning when dealing with complex subjects like econometrics, financial mathematics, statistics and any other module that requires the application and interpretation of sophisticated models to explain economic and financial realities. This research seeks to answer three main questions: (1) How can ePortfolios be integrated into the student learning experience to foster independent and self-regulated learning? (2) What are students' perceptions of the integration of ePortfolios in their learning? and (3) How can ePortfolios be used efficiently to ensure that students take ownership of their learning experience, thus helping to minimise direct instruction from faculty. Answers to these questions will further our understanding of how ePortfolios could be used to support learning in programmes that deal with complex subjects and how alternative types of assessment could be integrated as a complementary tool that helps students to reinforce and consolidate the concepts they learn. These forms of assessment allow students to go a step further by learning a concept, applying it and reflecting on the outcomes and their implications. We found that the ePortfolio provides an appropriate environment that combines learning by doing and offers a space to be reflexive and reflective on acquired knowledge. 
The remainder of the paper is organised as follows: the second section reports a general discussion on existing research into the importance of assessment to ensure that students are able to maximise their learning experience, and the need to move towards a self-regulated learning approach. The third section provides arguments on the value of ePorfolios in the assessment process, highlighting the importance of the tool. In section four we present some initial comments on how business disciplines could benefit from the integration of ePortfolios in the learning process. Section five discusses the research methodology used and describes the data collection procedures. The results are presented and discussed in section six, and finally the paper's main conclusions, limitations and notes for further research are presented in section seven.

\section{The Importance of Assessment to Enhance the Student Learning Experience}

A common problem in the education system is the amount of time and effort instructors spend in designing a course, selecting the most appropriate material and identifying all the resources that give learners adequate support. The assessment tools used to evaluate student progress and acquired knowledge lie at the centre of the process. When designing and selecting appropriate assessment tools the importance of timely and constructive feedback should be considered (Wilson and Scalise, 2006). Very often instructors' feedback is limited to the allocation of a grade, as in the case of final exams or midterm activities that are not always well prepared or well explained to students. However, we consider it more beneficial to follow an interactive approach that favours exchange between students and instructors, as in the case of continuous feedback throughout the course. This feedback helps students to identify their weaknesses and highlight areas that require attention and improvements (Bransford et al., 2000). Consequently, students should be self-aware of their flaws or knowledge limitations, and they should be able to think and reflect on the type of approach that will allow them to advance in their learning and to take suitable actions. Correctly designed assessments will promote a sustainable life-long learning experience and will prepare 
students to self-assess. We believe that students should be able to gradually build on new knowledge and skills by making connections with existing knowledge, thus helping them to develop a deep understanding of the subject matter (Wilson, Scalise, 2006).

However, good assessment practice appears to be a complex and challenging area for educators. Well-structured assessments add quality to the learning experience, as they help students to develop their metacognitive skills, and at the same time, provide feedback to instructors regarding course difficulties and highlight areas where students might be struggling. This information may lead instructors to introduce supplemental activities to support students. However, time and resources are a major constraint, as instructors' schedules are frequently overloaded and they might not have the time and the means to design extra activities that would help their students to progress and consolidate learnt concepts (Cross and Angelo, 1993). We consider that these issues may be solved by motivating students to take a more proactive approach to their learning, aimed at identifying needs and possible actions to support them as they progress in their studies. In this regard, the instructor should not be the focus of attention, and students should take the initiative to address and advance their own learning needs.

We find that students are reticent about traditional assessments and they question the value added or the relevancy of a single method of measuring their performance for the whole course. They suggest that these types of assessments only serve the purpose of achieving a grade, and make no contribution to retaining knowledge in the long-term. They consider this to be an unfair practice, as artificial and dull exercises do not measure qualities, skills and competences, and that in the particular case of exams, there is a great deal of pressure to meet short-term learning goals and achieve a grade that does not necessarily reflect their capacities and abilities. Students' main arguments highlight the tendency to quickly forget the material studied and they criticise the purpose of the whole exercise, as they are not able to retain what may be regarded as core, useful knowledge. We observed that our students were receptive to the introduction of alternative forms of assessments, 
as they are regarded as more effective and often helpful in connecting academic input to real situations. They also allow them to work continuously on the course and keep them engaged and motivated through the course work. Further, alternative assessments are perceived as rewarding to those students who consistently make the effort to learn, in contrast to those who rely on last-minute efforts (Sambel et al., 1997). Alternative forms of assessment may be less difficult and even more suitable to verify students' learning and to maintain higher levels of activity for longer periods. For example, some of our students regard websites or blogs as potential sources for creating a social learning medium that is less stressful than classic pen-and-paper essay writing. With the rapid growth of Information Technologies (IT) and their availability at HEIs, it seems feasible to accommodate innovative forms of assessment in order to "map individual trajectories of learning that go beyond the grades" (Wilson, Scalise, 2006, p.659).

However, beyond the potential of alternative assessment methods, a degree of scepticism still remains. One of the main shortcomings is the additional workload for students and instructors alike (Drew, 2001). Another limitation, which may affect the expected and desired results of implementing an innovative assessment practice, is a lack of personal motivation to participate, a fact that must be considered carefully by the instructor when designing his/her class assessments (Sambell et al., 1997). While alternative forms of assessment have great potential, the instructor should consider the characteristics of the class and the feasibility of the selected assessment to avoid the exercise turning into an unsatisfactory experience. The introduction of alternative forms of assessment requires effort, well-structured guidelines and commitment from both instructors and students.

\section{Portfolios as an Alternative Form of Assessment}

Slater (1996) reports a positive experience from students participating in portfolio assessments, as they remembered much more effectively and for longer periods what they learnt 
because they had worked on it in a continuous manner. Portfolios allow students to work on different tasks, to be creative in the application of principles and concepts, and to integrate their own views, reflections and critiques along the way. However, if the work in the portfolio is not properly outlined and grades are not clearly allocated to each of the tasks, the whole exercise might turn out to be an unfruitful and ineffective activity. Students will not be willing to put in the required efforts if they cannot clearly identify what is to be gained by it (Janssens et al., 2002).

The rapid growth of information technologies and their availability in the classroom open up the possibility of moving from traditional assessment practices towards ePortfolio-based assessments. We identify ePortfolios as promoters of self-regulated learning, with students taking full ownership of the knowledge-generating process in a more exciting and innovative way. The importance of creating a self-regulated learning culture cannot be underestimated, with educators playing a leading role in the implementation of this concept, a role that is crucial in the early stages of its application. The practice of ePortfolio assessment may be equally appropriate for both undergraduate and postgraduate students, if designed according to the learners' level, experience and goals. ePortfolios can be used to encourage students' involvement in the learning process from the very first day, which is equally important for both undergraduate and postgraduate students. Postgraduate students with some learning experience could benefit more from following this innovative practice and create quality material that they could find useful for revision and to stimulate memory over their course of studies.

\subsection{Background to ePortfolios}

Over the last decade we have witnessed changes in the educational paradigm; the learnercentred model is gaining ground, giving students more active participation as managers of their learning experience and greater responsibility for their own education as compared to the traditional educator-centred teaching model. In this context, technology has played a crucial role in providing 
alternative tools, such as ePortfolios, which favour the benefits of interconnectivity and the development of additional capabilities within the learning experience (Oliver and Whelan, 2011; von Konsky and Oliver, 2012). Likewise, the use of virtual portfolios extends students' autonomy, and their ability to self-regulate their learning process improves. At the same time they become more active and autonomous, and more critical of and reflective on their own work. In this way, the instructor's role appears to be transitioning towards that of moderator and facilitator rather than the main source of knowledge.

When instructors contemplate using ePortfolios, they should first consider the students and how to involve them in their learning process and encourage them to be more active and concerned about their education. An initial issue to consider is how to offer proper support in using the available technology and its potential applications. The instructor should be able to provide precise guidelines and clearly convey the goals to be achieved by continuously monitoring and mentoring students' progress. If the instructor is not able to design an appropriate strategy that clearly explains how students should work with the ePortfolio and what the main goals of the course are, then this resource will not enhance the learning process and the exercise will be unsatisfactory and frustrating. The central feature of this electronic tool is that it establishes a virtual space where participants can take advantage of the online working environment. The tool offers diverse possibilities to both students and instructors through real-time communication that helps to overcome the face-to-face limitations which seem to be a major constraint in traditional learning methods. This tool also has the potential to reorient the educational model towards a constructivist knowledge paradigm, where the student is the principal player and the instructor acts as a supporter and mentor in the learning process.

Students' perception and involvement have a direct impact on the success of ePortfolio implementation. In this regard, we need to be aware of the students' attitude towards active learning, and attention should be paid to the level of student enthusiasm and commitment (Baeten et al., 2010; 
and Leese, 2009). Identifying the benefits of using a virtual learning environment to encourage student engagement requires a great deal of attention from the instructor to assure a successful and constructive learning experience. De Lange et al., (2003) found that the use of virtual resources in the educational setting is a key factor in motivating and enhancing the learning process, and that students appear to be quite receptive to them. Moreover, Gülbahar and Tinmaz (2006) argued that students who were motivated and worked on their ePortfolios were able to enrich their learning experience. Furthermore, by using different ePortfolio applications, students are able to elaborate on their reflections and become familiar with the importance of using technologies and understanding their potential and value to their training (Doig, 2006; Zubizarreta and Millis, 2009).

The implementation of ePortfolios in has had a dramatic impact, particularly in higher education and beyond. Although the literature goes back to the late nineties (Resta and Laferriere, 2007; and Yancey, 2009), more recently significant studies have focused on students' experiences and the lessons learnt after introducing the ePortfolio as a key strategy for the consolidation of knowledge. Lopez-Fernández and Rodríguez-Illera (2009) explored students' perceptions, concluding that the students' experience has a positive impact, particularly in their personal development, when the ePortfolio is fully implemented and instructors are able to coordinate the use of the tool efficiently. Meyer et al., (2010) and Huang et al., (2012) stressed that ePortfolios contribute to enhancing the students' desire to learn and to develop strategies that are specifically related to self-regulated learning. On the other hand, pitfalls to effective implementation still exist. The exogenous factors we identified are technological innovation barriers, ignorance of the platform and the best way to use it, and lack of institutional support. Endogenous factors include reluctance to change, lack of confidence, discouragement and negative beliefs, lack of interest in instructors and lack of motivation in students, which lead to an implantation failure, or to a partial deployment in which no targets are met. 


\subsection{A Smooth Transition to ePortfolios}

We believe that ePortfolios could enable students to externalise their creativity, their critical thinking and their self-assessment skills. If this tool is implemented correctly, it could be a powerful learning instrument for knowledge generation and transmission. However, considering the drawbacks associated with ePortfolio implementation, students must be prepared for the transition from classic pen-and-paper assessments to a more creative way of completing their assignments. If students are introduced to the practice of completing assignments through ePortfolios from the first year in HEIs, they will be familiar with the procedures, and this familiarity will help them to spread their workload gradually and effectively manage the time required to complete their tasks. Experience tells us that students need time to adjust to the type of work required when using ePorfolios, and instructors need to be fully trained to exploit the tool and to offer proper support to their students. Through this study we endeavour to put forward some ideas on possible preparatory steps, which we consider helpful before the full implementation of ePortfolios as an efficient tool for classroom assessments.

Although students are attracted to the idea of alternative forms of assessment and are willing to engage actively in the classroom, they may not yet be ready for the completely new and independent learning experience. The learning process should be supported with clear explanations and monitoring of student perceptions, and instructors should be well versed in the use of the ePortfolio to be able to coach and support their students. The whole process needs to be explained to students and time to become familiar with the tool should be made available in the initial stages, otherwise students will feel under pressure from their instructor's demands and might not fully understand how to use the tool to support their course work (further explanations are given in section 5.3 below). 


\section{$4 \quad$ Assessing ePortfolios on Business Courses in HEIs}

The literature on the role of feedback and assessment in higher education demonstrates that students' learning improves substantially once they have benefitted from their instructor's comments and guidelines. Hence, offering constructive and timely feedback to ensure that students are able to integrate the comments they receive on their work is crucial to ensure that they develop the skills that lead them to take control of their own education and become self-regulated learners (Nicol and Macfarlane-Dick, 2006; Sadler, 1998; Pintrich and Zusho, 2002; Butler and Winne, 1995, Black and Wiliam, 1998).

The role of feedback in student assessment should focus on motivating students' positive reactions to the learning process. Students should pursue improvement, and the consolidation and application of skills learnt in the classroom that give them more confidence and enable them to regulate their own learning process according to their needs. We consider that ePortfolios could play a significant role in this process, as this tool allows students to organise and structure their work at their own pace. At the same time, the instructor is able to interact and monitor students' progress to ensure that their work complies with the basic requirements of the course. In addition, ePortfolios allow students to communicate with their peers in order to share their own experiences and learn from each other. Therefore, ePortfolios seem to encourage cooperation and collaboration outside the classroom and help students to share and reflect on their own work and also on their peers' efforts. If we consider that learning is now more commonly conceptualised as a process whereby students actively construct their own knowledge and skills (Barr and Tagg, 1995; DeCorte, 1996; Nicol, 1997), ePortfolios could play a major role in helping students to reflect on their own learning and in motivating them to create their own learning resources.

Consequently, we conducted a case study to examine the qualities of ePortfolios to support postgraduate students enrolled on business programmes where finance is a major component. Our 
case study explored how ePortfolios could be used to support technical subjects in business programmes involving a significant amount of autonomous work to ensure that students gain the basic financial skills. As a result, students' learning responsibilities have increased, but this does not seem to be reflected in how the assessment processes are undertaken in this new environment. In line with Nicol and Macfarlane-Dick (2006, p.17), if students are required to learn throughout life, they must be also equipped with the appropriate tools that allow them to develop their capacity to selfregulate their own learning, thus helping them to progress through higher education and strengthening their lifelong learning experience.

\section{$5 \quad$ Research Methods and Procedures}

HEIs have traditionally been dominated by an approach to learning and teaching in which instructors controlled the whole process, characterised by a certain degree of student passivity and a lack of involvement in their studies. In 2007 faculty at the Dublin Institute of Technology (DIT) in the Republic of Ireland were involved in learning and teaching courses looking to integrate technology in the learning process. The instructors then decided to bring the knowledge they had acquired and their learning skills to the classroom. The experiment aimed to introduce alternative teaching approaches supported by technology that sought to encourage and nurture students' participation and self-regulated learning. After two years of research into combinations of different methodologies and tools it was decided that the flexibility and variety of learning and teaching tools and artefacts offered by ePortfolios might make them a valuable instrument. As a result, late in 2008 the resource was introduced as an experiment to support postgraduate courses at DIT. In order to assess and analyse the experience, and after a careful review of available research methods that could add value to this study, we opted to use a case study method. According to Bogdan and Biiklen (1998, p. 54) a case study allows the researcher to develop a detailed examination of a particular event. Furthermore, the case study method gave us the opportunity to provide a rich and holistic 
account of a real life situation that would help us to communicate and add value to existing knowledge. Our case aims to provide a general assessment of the value of ePortfolios for business disciplines. The research was also supported by observation techniques, and questionnaires were used to gather relevant data to support our study.

\subsection{Research Sample}

The study is based on a sample of postgraduate finance students who assessed the efficacy of the ePortfolio as a learning tool. Our sample spanned four academic years (2008 to 2012) focusing on the MSc in Finance programme, which is limited to an average of twenty students per year, giving a final sample of eighty students who used ePortfolios to support their studies. The selected sample size and time period allowed for close monitoring on how students used the ePortfolio and helped us to examine their reactions to the tool. An analysis of four academic years enabled us to present a clear discussion on how the use of the tool evolved, and to provide a record of students' views and experiences. We mainly focused on subjects with a high level of complexity and that challenged students' understanding of current economic and financial issues. The ePortfolio was used to support subjects such as Portfolio Management, International Capital Markets, International Finance and Econometrics. The diversity of subjects allowed us to reflect on students' performance when dealing with different kinds of knowledge and helped us gather relevant information on the best techniques and ways to integrate the tool in the course.

\subsection{Data Collection Instruments}

The researchers prepared questions and assignments to support their respective courses with the basic requirement that students would answer and discuss the exercises set on their individual ePortfolio. In addition, a reflective section on the value added by the assignments and the ePortfolio was clearly explained to students, as this was the main source of information to support this research. 
Students were asked to reflect on their learning experience and encouraged to be critical of their assessments and to offer constructive suggestions on how the use of the ePortfolio could be improved. Informal discussions also took place, which led to formal observations and dialogues that evaluated the contributions the ePortfolios had made to the course. Our main goal was to learn how the ePortfolio could be efficiently integrated as a blended learning tool that encourages autonomous and self-regulated learning.

\subsection{Integration of ePortfolios in the Students' Learning Experience}

Figure 1 below summarises our proposal for the stages required to ensure proper implantation of the ePortfolio, according to our observations over the four years of study. We have identified five main steps to be followed for instructors to have a positive impact on their students and offer appropriate support by familiarising them with the use of ePortfolios.

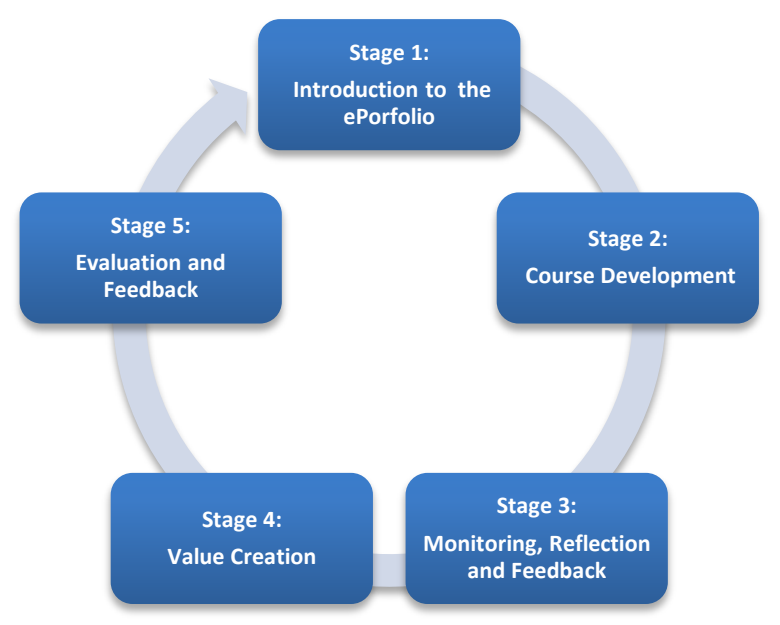

Fig. 1. ePortfolio implementation stages (source: the authors, 2013) 


\section{Stage 1: Introduction to ePortfolios}

This initial stage aims to encourage students to discover the tool's potential by themselves. The ePortfolio integrates various aspects of the student's life; instructors should therefore encourage them to complete their personal data on their own curriculum, hobbies and personal interests in an attempt to engage them with the tool. The objective is to build a connection with the tool, to enforce the sense of familiarity with the virtual space and to introduce them to the new dynamic class in which they take centre stage, as they are participating in their own learning process. Support and feedback from their instructor plays a key role at this early stage, which implies that the instructor must be proficient in the use of the tool. It is therefore advisable to introduce students to the virtual environment gradually and smoothly, without any pressures related to the learning goals at the beginning. At this stage, students should feel free to explore the tool and a knowledgeable instructor should guide them on how to manage and use their ePortfolio. Once students feel comfortable with the tool and they start developing an interest to explore further, the instructor can integrate module goals into the teaching process. Straightforward activities are appropriate at this initial stage and the benefit of inter-connectivity should be highlighted not only in the student-instructor relationship but also among peers. Such activities might include posting issues on the forum or creating a diary of class activities and encouraging students to explore what is published and add their own contributions. At this stage it is recommended that students present their initial work to the class, thereby allowing them to learn from each other, receive objective feedback from their instructor and share their concerns and difficulties. The aim of this type of activity is to build a sense of collaboration and cooperation in the classroom and to allow students to see their peers' input, which will stimulate them to think about their own work. 


\section{Stage 2: Course Development}

In accordance with the course goals, students are encouraged to use the self-managed ePortfolio to carry out the activities and additional course assignments. At this stage, it is appropriate to offer extra activities that facilitate students' self-development. Students' progress should be carefully monitored in this phase, paying particular attention to their motivation and willingness to explore the course material, and showing them how the ePortfolio can help them to make further progress in their learning. The instructor can offer guidance and tips to keep students engaged in the learning process and the use of the ePortfolio. At this stage the instructor should also monitor students' progress and start to offer individualised feedback on their progression and some initial assessment of their work, thus giving students a good understanding of their progress and the efforts that are required to meet the course goals. Students should be encouraged to clarify potential issues that keep them focused on their course work. During this second stage of the implementation process, the instructor should take a less prominent role and the focus of attention should be transitioning towards the students and their work.

\section{Stage 3: Monitoring, Reflection and Feedback}

In the third stage the instructor should offer comments and guidelines to give students more comprehensive feedback on their work. We recommend some initial grading, as this will give students a clear picture of their progress, and highlight the importance of working on their ePortfolios. Hence, it is very important for the instructor to offer constructive and timely feedback to enable students to incorporate his or her comments into their work and start to self-regulate their learning. During this phase, it is also important for students to realise the benefits of regular engagement with the learning process through involvement in the continuous assessments; at the same time, they become used to reflecting on their achievements and experiences. Constant 
engagement through regular assessments and developing the habit of writing reflective comments are two important components required to complete ePortfolios and that ensure that students are able to take ownership of their learning and become self-regulated. At this stage students should have a clear idea about the work they have to carry out and a set schedule for class presentations, and they should be fully aware of what their instructor expects from their work. The instructor should organise and facilitate class discussions that help to clarify doubts related to the course work, as well as monitoring the students' work on a continual basis. This approach will raise students' awareness of the importance of their work and preparing for their formal assessment. By this stage, students should be completely familiar with the technical aspects of the ePortfolio, and all their efforts should be focused on the course material.

\section{Stage 4: Value Creation}

Once students have overcome the difficulties arising from the full implementation of the ePortfolio and the work has been completed, an additional, unexpected dimension emerges, namely, students gain experience from taking part in their own long-life learning process. Not only is knowledge gradually consolidated, but students also become aware that the contents and the overall learning experience can be applied outside the classroom, specifically in the financial environment. They become more interested in exploring in greater depth the content and feedback from the previous stages and the re-feed process takes place. Enjoyment of learning is a sign of value added for the participants in the process; the contents they have learnt will have a greater future impact if their perception is positive. Moreover, if they believe that the information provided will be valuable in the future (in professional development or employability, for example), it will take on a greater importance. The ePortfolio therefore emerges as a sophisticated tool that drives this style of understanding and learning. 


\section{Stage 5: Evaluation and Feedback}

This stage includes the final assessment process, in which students receive their grades for their work in line with the criteria established at the beginning of the course. At this point, two aspects of the ePortfolio are evaluated: students reflect on their personal experience, and the instructor focuses on the formal grading of the work done during the semester/academic year. During this stage, students are asked to give their honest opinions in response to basic questions about their impressions and concerns following their learning experience with this virtual resource. Finally, the instructor assesses the ePortfolio; in brief discussions with colleagues, instructors aim to identify the value the tool has added to the learning process. This process enables them to identify areas that require further attention, which are then adjusted in the learning plans for future courses.

In answering our first research question: (1) How can ePortfolios be integrated in the student learning experience to foster independent knowledge? we devised a circular flow chart that identifies the basic steps required to equip students with the essential foundations to ensure their efficient use of the ePortfolios. We consider that the role of the instructor is fundamental during the first phase of implementation, a role that naturally diminishes in the process, as students gain understand of what they are required to do and take ownership of their own learning.

\section{Research Findings: the ePortfolio and the Student Experience}

This section discusses and analyses the main research findings of the case study into postgraduate students' experiences of using ePortfolios at DIT. Our main goal is to answer our second research question: (2) What were students' perceptions of their ePortfolio experience? To provide a detailed discussion in this section we divided the analysis into students' reflections and instructors' assessment of the ePortfolio. In our view, and following Rust (2001, p.154), a regular 
assessment task should be built in from day one in order to help students to engage seriously in the study process.

\subsection{Postgraduate Students' Reflections and Experience}

Diller and Phelps (2008) found that ePortfolios helped students to make connections between their course and extra-curricular activities, and reflect on how to obtain and present information. We found that in general, the ePortfolio helped postgraduate students to develop and enhance their written, communication and presentation skills. There is a common concern among instructors to reduce and minimise the informal tendencies in writing adopted by many students, such as abbreviating words or using internet slang, resulting from the proliferation of social media. It is essential, in our opinion, to restore the proper use and register of formal standards when using technology. To discuss our main findings we selected six responses from our postgraduate sample that reflected how students viewed the use of the ePortfolio and the value added to their studies and future careers.

Student one: "I am a big fan of the ePortfolio and I know that this view is shared by many of my fellow students. When you have completed an ePortfolio page and can look back on what you have done and what you have achieved in a semester it gives you a satisfaction that you cannot get from looking at a USB key full of files”,

This comment evidenced the enjoyment students obtained from developing their ePortfolio and the level of satisfaction they felt when looking back at their work and reflecting on their main accomplishments. This student's reflection is in line with existing research suggesting that portfolios contribute to stimulating personal growth and development at various stages of the learning process (Cutler, 1998; Heiss, 1998; Hutchings, 1998a; Langsam, 1998; New, Clawson, and Coughlan, 2000). We observed that students are able to grow through their work and experienced satisfaction when 
presenting their ePortfolio pages to their peers and their instructor. We also found that students who were motivated and worked on their ePortfolios had an enriched learning experience and felt satisfied with their work and course grades (Gülbahar and Tinmaz, 2006).

Student two: "I think that the ePortfolio platform is a great way for you to showcase your work to potential employers and I also plan to keep it in mind to ensure that I can quickly review all the work I have done for econometrics should I ever be in a position where I need it in the future, say for an interview or promotion. Rather than scrolling through files and old projects I can simply log into my ePortfolio and have all my work at my disposal"

Student three: The e-portfolio is a resource that, once developed, can be looked back upon at any future date. It essentially acts as a refresher of what topics were covered and what assessments I and the groups I was involved in produced during Semester 1 (i.e., International Capital Markets) and Semester 2 (i.e., Econometrics 2). This could be a valuable resource to have available when preparing for certain future work-related events (i.e., job interviews, presentations, meetings, etc.).

Student four: The e-portfolio can also act as an information brochure to prospective students looking to enrol in the MSc Finance course. For example, I have a friend from my previous undergraduate course who was inquiring about doing this course next year. He wanted to know how difficult the course was overall, and what kind of topics were covered in the different modules. Probably the best way for me to answer his questions is to show him this resource; it gives accurate descriptions of all the different topics and continuous assessments covered in the module throughout the year. So the e-portfolio is potentially very beneficial both to my myself and to my friend"

The comments by students two, three and four are in line with the views presented by Gough et al., (2003) indicating that personal development and planning could be supported through 
ePortfolios, as they have the potential to improve the learner's performance, especially when linked to action planning and goal setting. In this regard, students should be encouraged to develop ePortfolios in a professional manner that will help them in their future careers, as they could be used to showcase their academic work. We would advise that students focus on applying their knowledge and emphasising their reflective skills, which provide evidence of their capabilities to filter and process information. These qualities are invaluable and could help them in their professional careers.

\section{Student five "I found the ePortfolio a pleasant break from the usual work"}

The ePortfolio allows students to collect, archive, and publish their work in an organised manner. It helps them to make appropriate connections between theoretical and practical knowledge, integrating disciplines across different fields, themes and topics. While developing their ePortfolios, students are able to reflect on their learning and share it with their peers. They can also enjoy an alternative way of learning that is supported by up-to-date technologies that keep them engaged and focused on their work while they take a break from conventional ways of learning (Cambridge, Cambridge and Blake, 2009).

Student six: "Last semester I really disliked the ePortfolio as free time was at a premium for us in the class (due to the busy schedule of Semester 1) and I did not see the logic of having to devote so much time to developing the e-portfolio, as I did not really recognise its overall purpose. However this semester my perceptions towards the ePortfolio have completely changed. I now recognise that such a tool is helpful to us.

The ePortfolio could generate frustrations among students if it is not properly explained and integrated into the course activities (Wray, 2007). The whole process might take up a lot of time and students might not understand the main purpose of supporting their work with the tool. Our experience indicates that to ensure that learners are able to see the logic of developing the ePortfolio 
(as mentioned by one of our students), sufficient time and clear guidelines are needed. Students should be monitored and their work assessed to allow them to develop their own skills and encourage them to take control of their own education and become self-regulated learners (Nicol and Macfarlane-Dick, 2006; Sadler, 1998; Pintrich and Zusho, 2002).

Our third and final research question was: How could ePortfolios be used efficiently to ensure that students take ownership of their learning, thus helping to minimise direct instruction from faculty? In our view, the ePortfolio should be integrated as an additional assignment for students, thus avoiding the perception that it is an extra activity unconnected to the tasks they are set in their courses. Students should benefit from clear instruction right at the beginning of their course, in which the instructor clearly sets out all the required information. All the course objectives and goals should be explained to the students and they should be given enough leeway to become familiar with the work that is expected from them. The role of the instructor is crucial at the beginning of the process to ensure that all doubts and questions are clarified in a timely manner. The instructor should then begin to take a less central role, allowing students to work on their own and take responsibility for the course work. To ensure that students are progressing and that they do not lose direction and become confused, student-led presentations and discussions should be organised involving individual and collaborative work and minimising the need for direct teaching from their instructor.

\subsection{Instructor's Assessment and Reflections on the Value of ePortfolios}

Wray (2007, p. 1146) finds that "portfolios take time, are confusing to organize, and often lack a clear purpose resulting in student uncertainty and frustration”. Our own findings demonstrate that ePortfolios are a valuable tool, but instructors need to invest time and energy to minimise potential problems. To this end, sessions coordinated and monitored by the instructor were programmed at different stages of the courses to deal with ePortfolio management and technical issues. These sessions were supported with presentations from students to encourage them to share 
their outcomes with the class and provide general tips to their peers. In this way, students were encouraged to engage with their ePortfolio and they were made aware of the kind of work required, how they could maximise the use of their ePortfolio and also the kind of artefacts that they could integrate to aid their work. Chambers and Wickersham (2007) found that students valued being able to view their peers' ePortfolios because it reassured them about their own work or provided alternative perspectives. The whole process should be designed to motivate and encourage students' interaction, cooperation and collaboration, as in this way they will benefit from sharing experiences and ideas with their peers.

\section{$7 \quad$ Conclusions}

This case study explored how ePortfolios can be used to support students' learning experiences, where self-regulated assessment should be encouraged to motivate and ensure that students are taking ownership of their learning process and consequently their education. The main findings indicated that students' self-esteem and confidence increased once they became familiar with the ePortfolio environment and the work that was expected from them. The role of the instructor was identified as fundamental in the early stages of the learning process to help students become aware of the value of the ePortfolio. Guidance should therefore be provided during the first stages of the process, while students are still adapting to the new tool. Once initial fears have been dispelled and students are familiar with the tool, several dimensions that influence students' learning should be considered to help them develop self-regulated practices. At this stage, and as a result, the role of the instructor becomes that of a facilitator. The key pedagogical advancement afforded by ePortfolio use is that students become more aware of their learning and the importance of being independent and taking ownership of their work, and their enjoyment of the whole learning experience is enhanced.

\subsection{Research Limitations}


The suitability of ePortfolios is called into question in the case of large classes where proper monitoring and assessment is hampered because of the excessive workload involved for instructors. We believe that the tool could be used to offer support to large groups of students, but alternative ways of assessment need to be introduced to take into account the needs of this type of class. Another limitation of the study is the differentiation between the needs of undergraduate and postgraduate students in using ePortfolios to support their education, as each group will be at different stage of their learning curve. Finally, a further considering to be taken into account is the importance of curbing the temptation to gather material from other virtual sources that students have not prepared and presented themselves, a practice that undermines the whole objective of the learning process.

\subsection{Notes for Further Research}

Although obstacles clearly exist, we believe that ePortfolios could be used to create and foster constructive learning environments where students are encouraged to become self-regulated, reflective and autonomous in their course work and learning. It is our view that business schools and individual faculty should be encouraged to integrate technology in the classroom and further research is required to explore ePortfolio management and efficient ways to integrate the tool in the classroom. Therefore, in a subsequent project we will extent the analysis to cover complementary practices or alternatives to the ePortfolio that encourage quality and improve the teaching-learning process and that also stimulate educators to participate in new assessment methods that are clearly oriented to advancing students' self-regulated learning in HEIs. 


\section{References}

Asghar, M. (2012) The lived experience of formative assessment practice in a British university. Journal of Further and Higher Education, 36(2), 205-223.

Barr, R. B. \& Tagg, J. (1995) A new paradigm for undergraduate education, Change, 27(6), 13-25.

Black, P. \& Wiliam, D. (1998) Assessment and classroom learning, Assessment in Education, 5(1), 7-74.

Bogdan, R. C, \& Biklen, S. K. (1998). Qualitative research for education: An introduction to theory and methods. Boston: Allyn and Bac.

Butler, D. L. \& Winne, P. H. (1995) Feedback and self-regulated learning: a theoretical synthesis, Review of Educational Research, 65(3), 245-281.

DeCorte, E. (1996) New perspectives on learning and teaching in higher education, in: A. Burgen (Ed.) Goals and purposes of higher education in the 21st century (London, Jessica Kingsley).

Electronic Portfolios 2.0: Emergent Research on Implementation and Impact. Edited by Darren Cambridge, Barbara Cambridge, Kathleen Blake, Yancey Stylus, March 2009

Gough, DA. Kiwan, D. Sutcliffe, K. Simpson, D. Houghton, N. 2003. A systematic map and synthesis review of the effectiveness of personal development planning for improving student learning. In, Research Evidence in Education Library. London: EPPI-Centre, Social Science Research Unit, Institute of Education, University of London. At http://eppi.ioe.ac.uk/EPPIWeb/home.aspx?page=reel/review_groups/EPPI/LTSN/LT SN_intro.htm (accessed 21/10/2010).

Irwin, B., Hepplestone, S. (2011) Examining increased flexibility in assessment formats. 
iFirst Article. Assessment \& Evaluation in Higher Education, 1-13. DOI:10.1080/02602938.2011.573842

McLaren, S., V. (2012) Assessment is for learning: supporting feedback. International Journal of Technology and Design Education, 22, 227-245. DOI 10.1007/s10798-011-9195-z.

Nicol, D. J. (1997) Research on learning and higher education teaching, UCoSDA Briefing Paper 45 (Sheffield, Universities and Colleges Staff Development Agency).

Nicol, D \& Macfarlane-Dick, D. (2006). Formative assessment and selfregulated learning: a model and seven principles of good feedback practice. Studies in Higher Education, 31(2), 199-218.

Pintrich, P. R. \& Zusho, A. (2002) Student motivation and self-regulated learning in the college classroom, in: J. C. Smart \& W.G. Tierney (Eds) Higher Education: handbook of theory and research (vol. XVII) (New York, Agathon Press).

Read, B., Francis, B. (2005) Examining assessment in higher education: assessment as a socially situated practice. Assessment \& Evaluation in Higher Education Vol. 30 (3), 209-213.

Rust, C. (2002) The impact of assessment on student learning. How can the research literature practically help to inform the development of departmental assessment strategies and learner-centred assessment practices?

Sadler, D. R. (1998) Formative assessment: revisiting the territory, Assessment in Education, 5(1), 77-84.

Simpson-Beck, V. (2011) Assessing classroom assessment techniques. Active Learning in Higher Education 12 (2), 125-132. DOI: 10.1177/1469787411402482.

Struyven, K., Dochy, F., Janssens, S. (2005) Students’ perceptions about evaluation and assessment in higher education: a review, Assessment \& Evaluation in Higher Education, 30(4), $325-34$

The Institute for Learning and Teaching in Higher Education and SAGE Publications 
(London, Thousand Oaks, CA and New Delhi) Vol 3(2): 145- 158.

Vonderwell, S, Liang, X \& Alderman, K. (2009). Asynchronous discussions and assessment in online learning Journal of Research on Technology in Education, 39(3), 309-328.

Wilson, M., Scalise, K. (2006) Assessment to improve learning in higher education: The BEAR Assessment System. Higher Education, 52, 635-663. DOI 10.1007/s10734-004-7263-y. 